\title{
Recycling of air pollution control residues from municipal solid waste incineration into lightweight aggregates
}

\author{
Margarida J. Quina ${ }^{\mathrm{a}, *}$, João M. Bordado ${ }^{\mathrm{b}}$, Rosa M. Quinta-Ferreira ${ }^{\mathrm{a}}$ \\ ${ }^{a}$ CIEPQPF - Research Centre on Chemical Processes Engineering and Forest Products, Department of Chemical Engineering, University of Coimbra, Rua Sílvio Lima, 3030-790 \\ Coimbra, Portugal \\ ${ }^{\mathrm{b}}$ Associate Laboratory IBB, Department of Chemical Engineering, Instituto Superior Técnico, Av. Rovisco Pais, 1049-001 Lisboa, Portugal
}

\section{A R T I C L E I N F O}

Article history:

Received 24 May 2013

Accepted 15 October 2013

Available online 14 November 2013

\section{Keywords:}

APC residues

MSW incineration

Lightweight aggregates

Recycling

\begin{abstract}
A B S T R A C T
This work focuses on the assessment of technological properties and on the leaching behavior of lightweight aggregates (LWA) produced by incorporating different quantities of air pollution control (APC) residues from municipal solid waste (MSW) incineration. Currently this hazardous waste has been mostly landfilled after stabilization/solidification. The LWA were produced by pelletizing natural clay, APC residues as-received from incineration plant, or after a washing treatment, a small amount of oil and water. The pellets were fired in a laboratory chamber furnace over calcium carbonate. The main technological properties of the LWA were evaluated, mainly concerning morphology, bulk and particle densities, compressive strength, bloating index, water adsorption and porosity. Given that APC residues do not own expansive (bloating) properties, the incorporation into LWA is only possible in moderate quantities, such as $3 \%$ as received or $5 \%$ after pre-washing treatment.

The leaching behavior of heavy metals from sintered LWA using water or acid solutions was investigated, and despite the low acid neutralization capacity of the synthetic aggregates, the released quantities were low over a wide $\mathrm{pH}$ range.

In conclusion, after a washing pre-treatment and if the percentage of incorporation is low, these residues may be incorporated into LWA. However, the recycling of APC residues from MSW incineration into LWA does not revealed any technical advantage.
\end{abstract}

(c) 2013 Elsevier Ltd. All rights reserved.

\section{Introduction}

The municipal solid waste (MSW) incineration has been increasingly used in most of developed countries, with the advantages of energy recovery and high reduction in mass and volume of the initial wastes. For minimizing the negative impact on environment resulting from emissions to air, the flue gases must be cleaned. Currently, there are scrubbers, fabric filters and/or electrostatic precipitators to take out particulate and gaseous pollutants, before gases being released into the atmosphere. However, this cleaning procedure creates hazardous air pollution control (APC) residues, which require further management. This waste has been mostly treated by a stabilization/solidification technology with hydraulic binders (usually cement) and then landfilled in appropriate disposal sites (Chandler et al., 1997; Sabbas et al., 2003; Quina et al., 2008a). The main characteristics of concern of the APC residues are the high content of heavy metals and soluble salts. The sintering/thermal processes seem to be able to solve these problems (Wang et al., 1998, 2002; Sakai and Hiraoka, 2000;

\footnotetext{
* Corresponding author. Tel.: +351 239798 700; fax: +351 239798703 .

E-mail address: guida@eq.uc.pt (M.J. Quina).
}

Mangialardi, 2001; Wainwright and Cresswell, 2001; Dimech et al., 2008; Haiying et al., 2011; del Valle-Zermeño et al., 2013).

Besides, the ceramic industry uses high quantities of silicatebased natural raw materials and thus it is a possible field for ash utilization (Ferreira et al., 2003). In addition, particulate materials can be incorporated into ceramic pastes without pre-treatment, and toxic heavy metal (e.g. $\mathrm{Pb}, \mathrm{Cd}, \mathrm{Cr}, \mathrm{Ni}, \mathrm{Cu}$ ) initially present in the waste may be integrated in the final ceramic products, by choosing carefully the quantity of waste incorporated. In the literature there are references to studies involving this and similar wastes incorporation into ceramic materials, such as lightweight aggregates (LWA). In general, LWA can be obtained from natural resources (e.g. volcanic aggregates or pumice) or produced by thermal processes in kilns. The synthetic aggregates are ceramic products manufactured by thermal treatment of raw materials with expansive properties, such as perlite, vermiculite, clay and shale and industrial by-products (e.g. fly ash and slags) (Chandra and Berntsson, 2002). Lighter LWA may be obtained from coarser grain sizes made from a homogeneous paste of bloating clay, water and a small percentage of mineral oil (Chandra and Berntsson, 2002). The green pellets are sintered at high temperatures to obtain a glassy material characterized by an external hard ceramic shell and very 
porous core with holes of different sizes. The main properties of LWA are lightness, good thermal characteristics, sound insulation and fire resistance, low water absorption, chemically resistant against alkaline and acidic conditions, and high durability. Accordingly, LWA have been used to produce lightweight concrete, insulation materials, geotechnical fill, as well as used for soil engineering, in drainage systems and roofs.

In the literature there are several studies aiming to produce LWA using secondary materials (Ducman et al., 2002; Cheeseman and Virdi, 2005; Cheeseman et al., 2005; Quina et al., 2006; Chiou et al., 2006; Huang et al., 2007; Qiao et al., 2008; Gonzalez-Corrochano et al., 2009, 2012; Chen et al., 2010; Kourti and Cheeseman, 2010; Latosinska and Zygadlo, 2011; Tan et al., 2012; Hwang et al., 2012) such as combustion ashes, waste glass, sewage sludge ash, incinerator bottom ash, mining residues, heavy metal sludge, washing aggregate sludge, lignite coal fly ash, contaminated mine soil. In other cases, natural materials such as zeolitic rocks or volcanoclastites were considered as well (Gennaro et al., 2004, 2005).

To obtain lightweight aggregates it is necessary to heat raw materials at high temperatures and to entrap the released gases within a highly viscous liquid phase; during the cooling period an external glassy film with very low porosity, homogeneous and resistant is formed (Gennaro et al., 2004). The main sources of gases are the combustion reactions of organic compounds $\left(\mathrm{CO}_{2}\right.$ and water), the decomposition of carbonates $\left(\mathrm{CO}_{2}\right)$, the reduction of ferric iron $\left(\mathrm{O}_{2}\right.$ and $\left.\mathrm{CO}_{2}\right)$, the sulfides oxidation $\left(\mathrm{SO}_{x}\right)$ and other compounds that can be released from raw material $(\mathrm{F}, \mathrm{Cl})$. The commercial LWA are in general made from appropriate clays, by adding small amounts of oil to improve the gas release.

This study focuses on the analysis of the effect of the APC residues (with and without washing pre-treatment) on the main technological properties of LWA as well as on the environmental impact due to leaching processes with water and acidic solutions.

\section{Materials and experimental procedures}

\subsection{Materials}

In our work, specific natural clay supplied by an industrial plant from the central region of Portugal, that processes about $24 \mathrm{t} / \mathrm{h}$ of clay, was considered. The APC residues were collected from a mass burning incinerator that has a nominal capacity of $28 \mathrm{t} / \mathrm{h}$, comprising gas cleaning residues from economizer, semi-dry scrubbers (with lime and activated carbon) and fabric filters. In addition, about $1 \%$ of oil (also supplied by the industry) and $20-25 \%$ of water were used in the formulations tested. Both APC residues and natural clay were characterized in our previous works (Quina and Quinta-Ferreira, 2002; Quina et al., 2006, 2008b, 2009, 2010, 2011a, 2011b). However, Table 1 summarizes the most important properties of the materials used in this study.
The APC residues were tested as-received from the industrial plant and after a washing pre-treatment with water. The washing treatment consisted of mixing the residue with 10 times of distilled water (L/S 10), during $10 \mathrm{~min}$. The suspension was then filtered and the solids were dried over night at $105^{\circ} \mathrm{C}$. The washing treatment aimed at removing water soluble compounds, in particular the chlorides.

\subsection{Production of $L W A$}

The industrial process for producing LWA involves a tubular kiln with an angle of tilt less than $5^{\circ}$ and with two different zones: $40 \mathrm{~m}$ long for drying the particles with a slow rotation (residence time of about $1.8 \mathrm{~h}$ ); $20 \mathrm{~m}$ long where firing takes place at about $1170{ }^{\circ} \mathrm{C}$ (residence time of $8-10 \mathrm{~min}$ ). The granules are fed at the higher end of the kiln in a counter flow process, and as the material moves along the tube the expansion takes place. However, in our laboratory it was not possible to simulate this process, but the industrial methodology used for quality control was followed. The raw materials (waste, clay, water and oil) were thoroughly mixed according to the different formulations summarized in Table 2, including clay, APC residues, about $20 \%$ of water and $1 \%$ of oil. For each case, spherical pellets were formed by hand, with mean mass values and median diameters reported in Table 3. Indeed, an initial attempt was made to use a rotary drum pelletiser, but since the size and weight of the granules were very different, it was difficult to replicate the tests in the laboratory. Following the conditions used for quality control at the industrial plant, the LWA were obtained by drying at $200{ }^{\circ} \mathrm{C}$ (at least $2 \mathrm{~h}$ ) in a first step and then by firing the spherical pellets in a chamber furnace oven at $1170{ }^{\circ} \mathrm{C}$ (during $8 \mathrm{~min}$ ) over solid $\mathrm{CaCO}_{3}$.

\subsection{Technological properties}

The bulk density, $\rho_{b}$, was determined in triplicate by weighing the mass of one litter of fired aggregates, which is also the method used at industry and recommended in the standard EN 1097-3. The apparent specific density, $\rho_{a}$, of LWA was determined through three methods: Met1 - using Archimedes' principle with water (in triplicate), considering 10 aggregates Eq. (1); Met2 - assuming a spherical geometry, Eq. (2); Met3 - based on the displacement method by immersing 6 aggregates in a certain amount of sand, $V_{f}$, and measuring the initial volume of sand in a graduated cylinder, $V_{\text {sand, }}$ Eq. (3).

$$
\begin{aligned}
\rho_{a, 1} & =\frac{M_{A}}{M_{1}-M_{2}} \rho_{\mathrm{H}_{2} \mathrm{O}} \\
\rho_{a, 2} & =\frac{6 M_{A}}{\pi D^{3}}
\end{aligned}
$$

Table 1

\begin{tabular}{|c|c|c|c|c|c|c|c|c|c|c|c|c|c|}
\hline & \multicolumn{7}{|c|}{ Main oxides (\%) } & \multicolumn{6}{|c|}{ Total elemental content (mg/kg) } \\
\hline & $\mathrm{SiO}_{2}$ & $\mathrm{Al}_{2} \mathrm{O}_{3}$ & $\mathrm{Fe}_{2} \mathrm{O}_{3}$ & $\mathrm{CaO}$ & $\mathrm{MgO}$ & $\mathrm{Na}_{2} \mathrm{O}$ & $\mathrm{K}_{2} \mathrm{O}$ & $\mathrm{Pb}$ & $\mathrm{Cr}$ & $\mathrm{Cu}$ & $\mathrm{Ni}$ & $\mathrm{Cd}$ & $\mathrm{Zn}$ \\
\hline Clay & 55.4 & 18.2 & 8.0 & 1.9 & 3.9 & $<0.5$ & 4.3 & nd & nd & nd & nd & nd & nd \\
\hline $\mathrm{APC}_{\text {residues }}$ & 14.1 & 7.4 & 2.3 & 41.9 & 1.0 & 3.7 & 3.2 & 1,924 & 232 & 456 & 121 & 57 & 4,308 \\
\hline \multirow[t]{3}{*}{$\mathrm{APC}_{\text {washed }}$} & 18.7 & 9.8 & 3.1 & 36.2 & 2.2 & 1.3 & 0.8 & nd & nd & nd & nd & nd & nd \\
\hline & & & & \multicolumn{10}{|c|}{ Measured in the eluate $(\mathrm{L} / \mathrm{S}=10$; concentration in $\mathrm{mg} / \mathrm{kg}$ ) } \\
\hline & Moisture (\%) & LOI $(\%)$ & $\rho_{\mathrm{r}}\left(\mathrm{g} / \mathrm{cm}^{3}\right)$ & $\mathrm{pH}$ & $\mathrm{EC}(\mathrm{mS} / \mathrm{cm})$ & TDS $(\mathrm{g} / \mathrm{kg})$ & $\mathrm{Pb}$ & $\mathrm{Cr}$ & $\mathrm{Cu}$ & $\mathrm{Ni}$ & $\mathrm{Cd}$ & $\mathrm{Zn}$ & $\mathrm{Cl}^{-}$ \\
\hline Clay & 15 & 6.6 & 2.66 & 8.49 & 0.346 & 2.65 & $<0.9$ & $<1.17$ & $<0.9$ & $<1.45$ & $<0.07$ & 0.23 & ND \\
\hline $\mathrm{APC}_{\text {residues }}$ & 0.85 & $8.3^{*}$ & 2.52 & 12.5 & 37.5 & 222 & 324 & 5.97 & 1.38 & 2.54 & 0.15 & 50.5 & 98,400 \\
\hline $\mathrm{APC}_{\text {washed }}$ & 0.93 & nd & nd & 12.1 & nd & 24.5 & 130 & 9.0 & $<0.9$ & $<1.45$ & $<0.07$ & 18.0 & ND \\
\hline
\end{tabular}

Properties of the clay, APC residues as received and after washing.

Loss on ignition measured at $750{ }^{\circ} \mathrm{C}$; nd - not determined; ND - not detected by titration with $\mathrm{AgNO}_{3}$. 
Table 2

Formulations tested in the laboratory experiments.

\begin{tabular}{|c|c|c|c|c|c|c|c|c|c|}
\hline \multirow[t]{2}{*}{ Reference } & \multicolumn{7}{|c|}{ APC residues as-received } & \multicolumn{2}{|c|}{ APC residues washed } \\
\hline & Wo & W1 & W2 & W3 & W4 & W5 & W10 & W5_w & W10_W \\
\hline Clay (\%) & 100 & 99 & 98 & 97 & 96 & 95 & 90 & 95 & 90 \\
\hline Residues (\%) & 0 & 1 & 2 & 3 & 4 & 5 & 10 & 5 & 10 \\
\hline
\end{tabular}

Table 3

Mean mass and median diameters of unfired granules.

\begin{tabular}{|c|c|c|c|c|c|c|c|c|c|}
\hline \multirow[t]{2}{*}{ Reference } & \multicolumn{7}{|c|}{ APC residues as-received } & \multicolumn{2}{|c|}{ APC residues washed } \\
\hline & wo & W1 & W2 & W3 & W4 & W5 & W10 & W5_w & W10_W \\
\hline Mean mass $(\mathrm{g})$ & 1.47 & 1.41 & 1.47 & 1.44 & 1.40 & 1.43 & 1.48 & 1.29 & 1.14 \\
\hline Median diameter (mm) & 11.4 & 11.2 & 11.2 & 11.3 & 11.3 & 11.4 & 11.6 & 11.2 & 11.1 \\
\hline Number of granules analyzed & 105 & 162 & 197 & 162 & 134 & 184 & 159 & 217 & 164 \\
\hline
\end{tabular}

$\rho_{a, 3}=\frac{M_{A}}{V_{f}-V_{\text {sand }}}$

where $M_{1}$ is the mass of the pycnometer filled with water $(\mathrm{g}), M_{2}$ mass of the pycnometer filled with water and aggregates $(\mathrm{g}), M_{A}$ mass of the aggregates $(\mathrm{g}), \rho_{\mathrm{H} 2 \mathrm{O}}$ specific gravity of water $\left(\mathrm{g} / \mathrm{cm}^{3}\right)$, $D$ the mean diameter of the aggregates $(\mathrm{cm})$.

The bloating index (BI) was assessed in terms of the diameter increase after firing, Eq. (4)

$B I=\frac{D-d}{d} \times 100$

where $D$ is the mean diameter of sintered aggregates $(\mathrm{cm})$ and $d$ the mean diameter of green pellets $(\mathrm{cm})$. The particle size change of aggregates before and after sintering was measured by using a pachymeter. BI parameter can also be measured in terms of volume ratio, representing in this case the number of times that the volume increases during the firing process (Gennaro et al., 2004).

The compressive strength was determined according to the industrial procedure (DIN 4226 - Part 3), by using a press Tecnilab LST. The LWA are placed in a vessel with a capacity of $1 \mathrm{~L}$, and then the force required to cause a lowering of $20 \mathrm{~cm}$ for $100 \mathrm{~s}$ was recorded.

The water absorption capacity (WAC) was determined following the standard EN 1097-6, by measuring the increase in the mass of the oven dry sample through immersion in water using a pycnometer at $22 \pm 1{ }^{\circ} \mathrm{C}$, according to Eq. (5):

$W A C=\frac{M_{W}-M_{A}}{M_{A}} \times 100$

where $M_{w}$ is the mass of the sample after a specific period of immersion (d), $M_{A}$ the mass of the dry aggregates. The method allows the assessment of the WAC at specific times, and in our study, measurements were made at 5, 15, 30 and 45 min and 1, 2, 4, 6, 9 and $24 \mathrm{~h}$.

The porosity of LWA was evaluated only for formulation W0, at three levels: whole aggregate crushed, external shell and core part. The techniques considered were mercury porosimetry, Micromeritics - PoreSizer 9320, and helium pycnometry, Micromeritics AccuPyc 1330 . In the mercury porosimetry, the pressure was increased from 1.5 psia to about 30,000 psia, and due to the size of $\mathrm{Hg}$ atoms macro and mesopores were characterized.

\subsection{Leaching properties}

For analyzing the leaching behavior of LWA, several pellets of each formulation were crushed to less than $1 \mathrm{~mm}$. Then, the compliance tank leaching test based on DIN 38414-S4 (superseded by
EN 12457-2) and the pH dependence test (prEN 14429) were performed. For each of those tests, at least two replicates were conducted. The compliance test involved one stage batch using distilled water at a liquid to solid ratio (L/S) of $10 \mathrm{~L} / \mathrm{kg}$ for $24 \mathrm{~h}$, conducted at natural $\mathrm{pH}$. On the contrary, in the $\mathrm{pH}$ dependence test, a series of subsamples were mixed with solutions of varying acidity with $\mathrm{L} / \mathrm{S} 10 \mathrm{~L} / \mathrm{kg}$. In practice, ten solutions with different final $\mathrm{pH}$ values were prepared, covering the minimum range of 4-12 (Quina et al., 2009). The suspensions were shaken on a rotary agitator (Heidolph Reax 20) for $48 \mathrm{~h}$ in closed vessels. The leachate was then separated by filtering through a $0.45 \mu \mathrm{m}$ membrane filter and the $\mathrm{pH}$ was recorded before acidification prior to metal analysis. The pH dependence test allows the assessment of the buffering capacity of the material or acid neutralization capacity (ANC), which affords perception in the sensitivity of the materials under analysis to externally imposed conditions. Metals were quantified by flame atomic absorption spectroscopy, Perkin Elmer - 3300, chlorides and sulfates were quantified by ion chromatography, Waters Action Analyzer, with a $100 \mu \mathrm{L}$ loop.

\section{Results and discussion}

\subsection{Morphology}

The outer surface of LWA may be observed in Fig. 1 for formulations with only clay (W0), incorporating increasing amounts of APC residues as-received from $1 \%$ to $10 \%$ (W1, W2, W3, W4, W5, W10) and also using $5 \%$ and $10 \%$ of washing APC residues (W5_W and W10_W). By visual observation of the outer surface of LWA, a dense glassy outer shell is noted. W0 is the reference case, and it is perceptible that the increasing incorporation of waste leads to irregular surfaces, mainly for formulations W4, W5 and W10. By comparing W5 with W5_w it is clear that the washing treatment has a positive contribution to the smoothness of the surface of the particles. The replacement of $10 \%$ of clay was very detrimental for the external appearance of LWA. In addition, as predicted through the Riley diagram (Quina et al., 2006) both incorporations of $10 \%$ with and without washing significantly reduce the bloating process.

\subsection{Technological properties of sintered LWA}

Fig. 2a shows that although the initial median diameter, $d_{50}$, were in the range of $11.1-11.6 \mathrm{~mm}$, after the firing process the LWA exhibits $d_{50}$ in the range of $16.9-21.2 \mathrm{~mm}$. Fig. 2b illustrates for each formulation tested the median diameter before and after firing plus the associated standard deviation. Though we tried to 

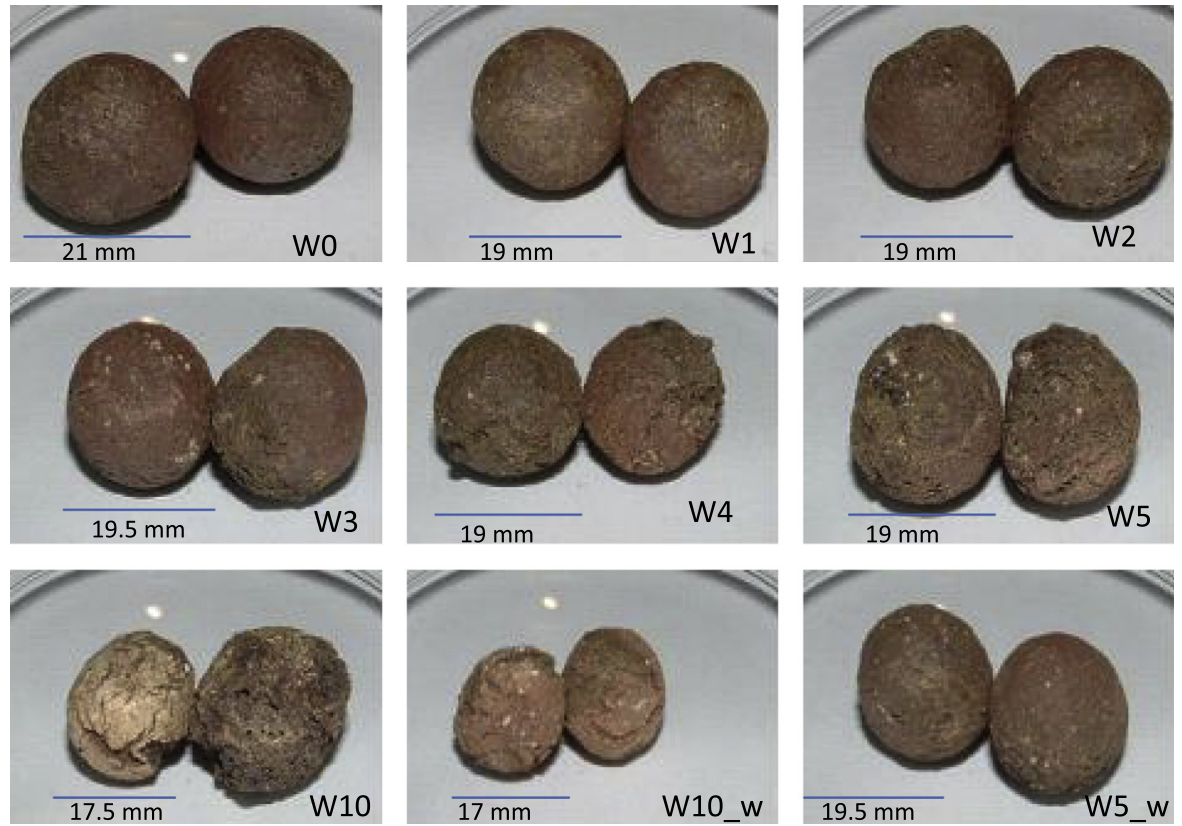

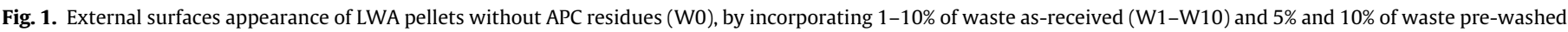
(W5_w and W10_W).
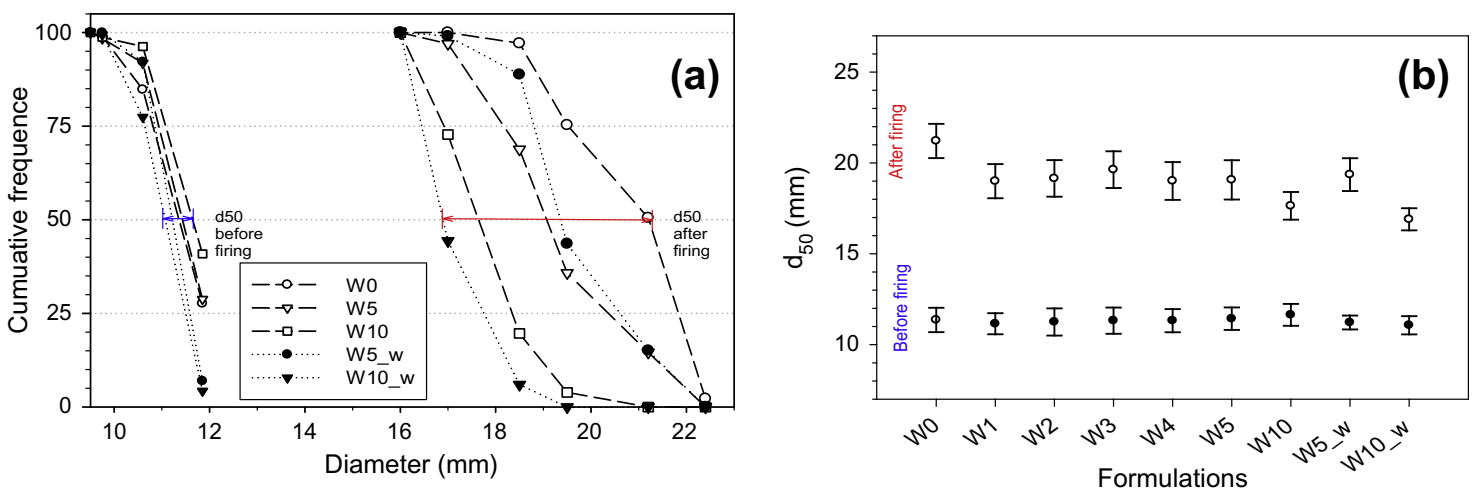

Fig. 2. (a) Granules size distribution and (b) comparison of median diameter before and after firing.

form spherical pellets of similar diameter, after firing the distribution became larger for all formulations (higher standard deviations), and this created some difficulties for comparison purposes.

The bloating index (BI) measured as a percentage of expansion of the material during the firing process, Fig. 3, decreased with increasing percentage of incorporation. For the base case W0, the

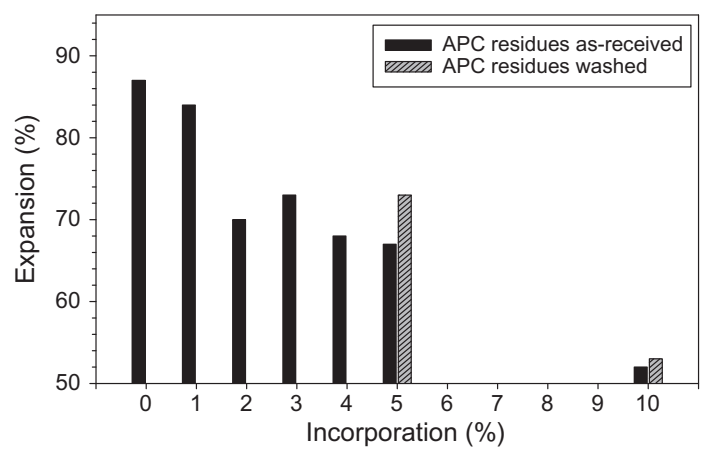

Fig. 3. Percentage of expansion of LWA as a function of the formulation. observed BI was $87 \%$, whereas for W10 that index decreased for $52 \%$. This means that the waste hampers the expanding process. In fact, when the composition of the APC residues was represented in the Riley ternary diagram (Quina et al., 2006), by plotting the amount of $\mathrm{SiO}_{2}, \mathrm{Al}_{2} \mathrm{O}_{3}$, and the fluxing $\left(\mathrm{Fe}_{2} \mathrm{O}_{3}+\mathrm{CaO}+\mathrm{MgO}+\mathrm{Na}_{2-}\right.$ $\mathrm{O}+\mathrm{K}_{2} \mathrm{O}$ ), it was observed that it falls outside the bloating area. Only replacements lower than $5 \%$ led to formulations inside the bloating region. By using washed APC residues, the decrease in the expansion is not so significant, being in this case only $16 \%$.

The variation of density of fired LWA with the percentage of incorporation is shown in Fig. 4 . The bulk density, $\rho_{b}$, rises as the amount of APC residues increase, meaning that by replacing a certain amount of clay by waste the LWA become heavier. In fact, the value observed for W0 was about $152 \mathrm{~g} / \mathrm{L}$ and for W10 $239 \mathrm{~g} / \mathrm{L}$. Considering as example the case of $5 \%$ of APC residues (W5) the increase in the bulk density was about $19 \%(181 \mathrm{~g} / \mathrm{L})$, whereas for pre-washed APC residues, the replacement of $5 \%$ led to an increase of only $13 \%$. Regarding the apparent specific gravity, $\rho_{a}$, the values obtained with Eqs. (1)-(3) were also represented in Fig. 4. The method used in industry for quality control, $\rho_{a, 3}$, resulted in lower estimates, ranging from 0.27 to $0.45 \mathrm{~g} / \mathrm{cm}^{3}$. According to the experimental procedures involved, the method based on the 

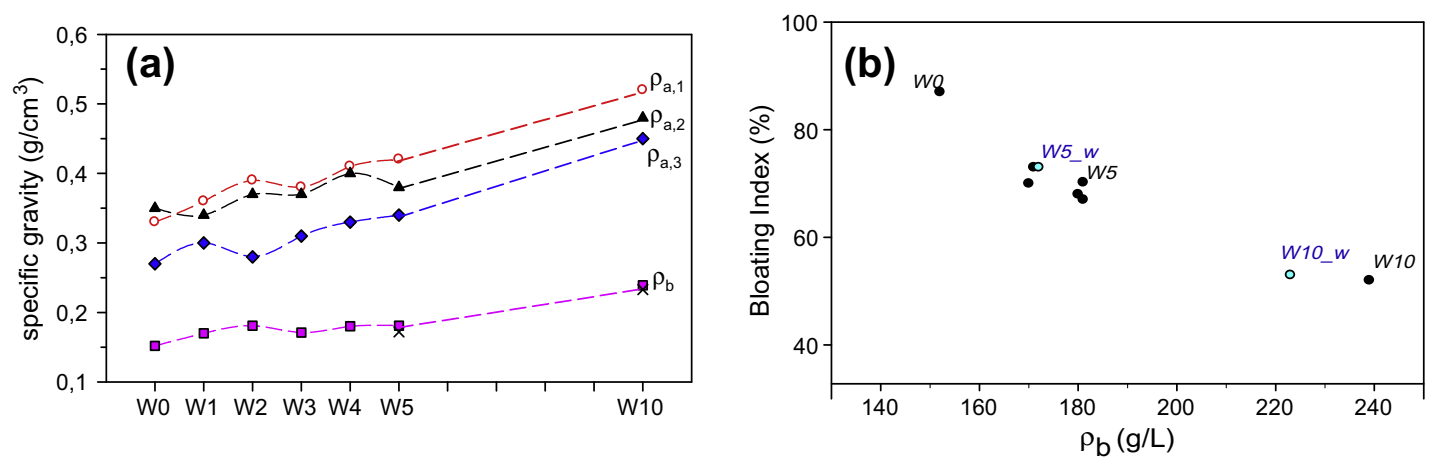

Fig. 4. (a) Apparent $\left(\rho_{a, 1} ; \rho_{a, 2} ; \rho_{a, 3}\right)$ and bulk specific gravity $\left(\rho_{\mathrm{b}}\right)$ of LWA as a function of the formulation; (b) Bloating index as a function of bulk density.

Archimedes' principle using water, $\rho_{a, 1}$, is probably the most accurate one, but also the most time consuming. Thus, the apparent specific gravity is in the range of 0.33 (for W0) to $0.52 \mathrm{~g} / \mathrm{cm}^{3}$ (for W10). This property was not measured for the cases W5_W and W10_w. Fig. 4b shows that, as expected, there is a strong correlation between the bloating index and the bulk density of the material. It should be noted that the expansion of the aggregates during the process of firing is driven by the release and entrapment of gas in the solid matrix. Therefore, LWA with lower bulk densities correspond to higher bloating indexes.

The compressive strength is represented in Fig. 5a as a function of the \% of APC residues incorporation, and also in this case an increase is observed as the amount of APC residues rise, with the exception of formulations W1 and W2. The behavior observed for W1 and W2 may be due to the fact that the $d_{50}$ was slightly lower than it should have been (Fig. 2b). Taking as example the $5 \%$ of replacement, an increase of $36 \%$ in the compressive strength is observed when compared to the reference case (W0). The washing of APC residues led to slightly higher compressive strengths. In Fig. 5b it was represented the compressive strengths of commercial LWA and the ones produced in laboratory conditions as function of the median diameter. In general, as expected, the strength of commercial LWA is significantly higher than the ones produced in laboratory conditions, but in any case as the diameter increases the compressive strength drops. It should be noted that the best commercial LWA must be resistant with dense continuous surface shell but with low density (porous ceramic cores) (Cheeseman and Virdi, 2005). According to our results, by replacing a percentage of clay with APC residues, the compressive strength becomes higher but due to an increase in the bulk density, and thus this is considered a disadvantage.

Regarding the water absorption capacity (WAC) of LWA, this is assumed as one of the most important properties to be determined, especially aiming at producing lightweight concrete. In the literature, there are references indicating that WAC should be as low as possible (Cheeseman and Virdi, 2005); but others refer that the idea of conducting a pre-saturation of LWA may have a beneficial effect of supplying internally curing water (Castro et al., 2011). However, if the LWA were used at dry conditions, they could interfere to a great extent with the hydration reactions of cement by removing water. Fig. 6a represents the rate at which dried LWA absorb water over $24 \mathrm{~h}$, and Fig. $6 \mathrm{~b}$ the normalized absorption (calculated as the ratio between the actual value and the final total absorption after $24 \mathrm{~h}$ ) during the first six hours, where it was also included the formulations with washed APC residues (W5_w and W10_w). The water absorption increased over time, but in the first two hours the rate of absorption was higher. Indeed, the normalized data showed that within the first two hours, the absorption reached more than $50 \%$ of the final WAC. It is interesting to note that the lowest rates are observed for W0 (base case) and for W5_w, and the highest initial rate occurred for W10. Similar trends can be found in literature for commercially available LWA (Castro et al., 2011), where values of $6 \%$ and $30 \%$ were attained at $24 \mathrm{~h}$ of immersion. Fig. 7a shows WAC at $24 \mathrm{~h}$ as a function of the \% of the incorporation of APC residues and an increase is detected up to $5 \%$ of replacement. In this case the WAC is near $21 \%$, against $11.5 \%$ for aggregates produced by using only clay. The commercial LWA (Leca ${ }^{\circledR}$ ) showed absorption of about $30.5 \%$. When the APC residues were previously washed, the WAC decreases until 14.8\% (for W5_w) which may represent an advantage for the final product. For the incorporation of $10 \%$, the WAC decreases, and this is a consequence of the fact that the expansion in this case is reduced (only $50 \%$ ) and then the pores structure is not well developed. In Fig. $7 \mathrm{~b}$ the water absorption is represented against the bloating index (expansion) for the cases that the residues were pre-washed (W5_w and W10_w) and used as-received (W1, W3, W4, W5 and W10). By comparing, for example, the results obtained for the formulations W5 and W5_w, it is clear that the washing process is
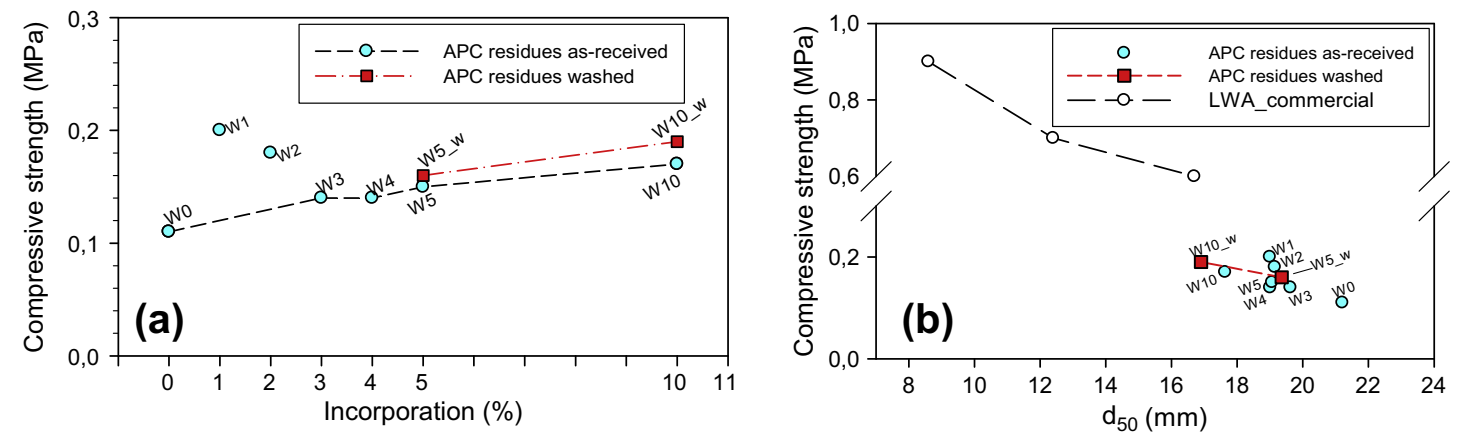

Fig. 5. Compressive strength of LWA as a function of (a) the formulation; (b) median diameter. 

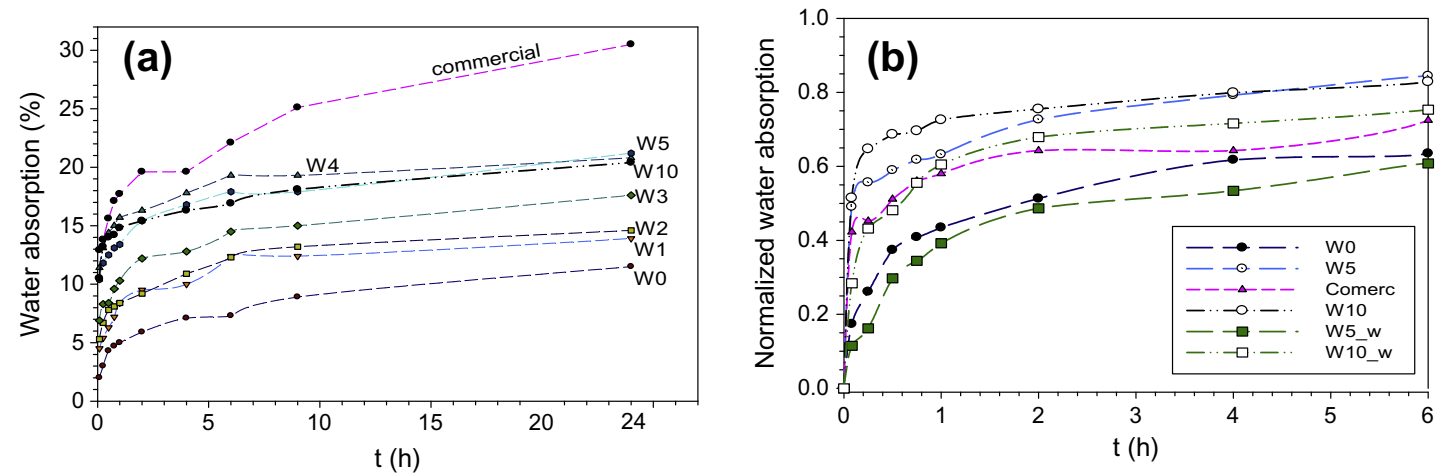

Fig. 6. (a) Water absorption of LWA over 24 h; (b) Normalized water absorption (referred to the total WAC after $24 \mathrm{~h}$ ) for the initial 6 h.
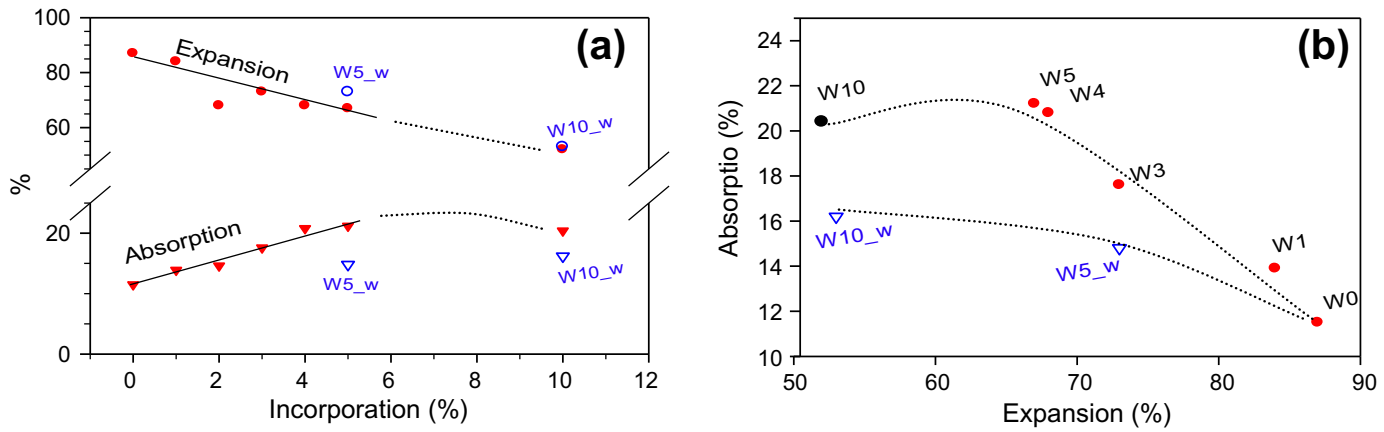

Fig. 7. (a) Water absorption capacity and expansion of the LWA as a function of the incorporation of APC residues; (b) as a function of expansion.

advantageous since it allows higher bloating index and lower water absorption.

For characterizing the porous structure of LWA, some aggregates W0 were disintegrated and divided into the dense continuous surface layer (external shell) and the low density internal core. Table 4 summarizes the results obtained through mercury porosimetry and helium pycnometry $\left(\rho_{\mathrm{r}}\right)$. The former technique allowed to estimate the open porosity of each fraction at about $81 \%$ for the internal core and 55\% for the external shell. The total porosity (closed plus open), $\varepsilon$, indicated in Table 4 (89.3\% and $61.9 \%$ for the internal and external parts) was determined by Eq. (6)

$\varepsilon=\left(1-\frac{\rho_{a}}{\rho_{r}}\right) \times 100$

where $\rho_{a}$ is the apparent density $(\mathrm{g} / \mathrm{mL})$ and $\rho_{r}$ the real density $(\mathrm{g} /$ $\mathrm{mL}$ ). The closed porosity was calculated by difference between total and open porosity, and, according to Table 4, 7.9\% for the internal part and $7.2 \%$ for the external shell were the values found. Similar figures were indicated in literature (Latosinska and Zygadlo, 2011) for lightweight aggregates incorporating sewage sludge as expanding

Table 4

Results from mercury intrusion porosimetry and helium pycnometry for LWA with formulation W0.

\begin{tabular}{lcc}
\hline & Internal core & External shell \\
\hline Pore median diameter, $d_{\text {poro,50, }}(\mu \mathrm{m})$ & 1.280 & 0.227 \\
Mean pore $(4 \mathrm{~V} / \mathrm{A}), \bar{d}_{\text {poro }}(\mu \mathrm{m})$ & 0.362 & 0.059 \\
Bulk density, $\rho_{b}(\mathrm{~g} / \mathrm{ml})=\rho_{a}$ & 0.265 & 0.922 \\
Skeletal density, $\rho_{S k}(\mathrm{~g} / \mathrm{ml})$ & 1.421 & 2.059 \\
Real density, $\rho_{r}(\mathrm{~g} / \mathrm{ml})$ & 2.470 & 2.395 \\
Open porosity $(\%)$ & 81.4 & 55.2 \\
Total porosity $(\%)$ & 89.3 & 61.9 \\
Closed porosity $(\%)$ & 7.9 & 7.2 \\
\hline
\end{tabular}

agent. It is important to note that it was not possible to analyze adequately a whole aggregate through mercury porosimetry due to logistical limitations of the sample holder, whereas helium pycnometry indicated a real density of $2.44 \mathrm{~g} / \mathrm{cm}^{3}$.

\subsection{Leaching properties}

Based on holistic approaches, our study aims to reduce the environmental impact of APC residues, but without the shift of the pollutants from solid to liquid streams. In this scope, some studies stressed that the leaching behavior of synthetic aggregates should be taken into consideration to evaluate the environmental effect on the various stages of its use (van der Sloot et al., 2001). Table 5 shows the results measured in leaching solutions of milled LWA extracted with water. Thus, it can be concluded that the toxic heavy metals $\mathrm{Pb}, \mathrm{Cd}, \mathrm{Zn}, \mathrm{Cr}$, Ni and $\mathrm{Cu}$ were below to the detection limits (DL) of the flame atomic absorption spectroscopy. It is important to note that the APC residues release high concentration of these elements in similar leaching conditions (for instance, about $324 \mathrm{mg} / \mathrm{kg}$ of $\mathrm{Pb}$ were observed) (Quina et al., 2008b). Therefore, for the formulation W10, a minimum release of $32 \mathrm{mg} / \mathrm{kg}$ would be expected if immobilization during the sintering process had not occurred. Regarding the major species, such as K, Na and Ca similar results were obtained for the different formulations. However, the concentration of chlorides rises as the percentage of APC residues increase from $0 \%$ to $10 \%$ (W0 to $\mathrm{W} 10$ ). The results obtained for W5_w and W10_w indicated, as expected, that after washing almost all chlorides were removed.

In addition, the $\mathrm{pH}$ dependence test has been carried out for assessing the release of heavy metals and the buffering capacity of the material. Indeed, one of the most important properties affecting the $\mathrm{pH}$ of the leachate is the acid or base neutralization capacity (ANC/BNC) (Sabbas et al., 2003). These parameters measure the capacity of a system to neutralize the influence of acids 
Table 5

Leaching quantities for LWA tested with water for $24 \mathrm{~h}(\mathrm{mg} / \mathrm{kg})$.

\begin{tabular}{|c|c|c|c|c|c|c|c|c|c|c|c|}
\hline & $\mathrm{Pb}$ & $\mathrm{Cd}$ & $\mathrm{Zn}$ & $\mathrm{Cr}$ & $\mathrm{Ni}$ & $\mathrm{Cu}$ & K & $\mathrm{Na}$ & $\mathrm{Ca}$ & $\mathrm{Cl}^{-}$ & $\mathrm{SO}_{4}^{2-}$ \\
\hline WO & $<\mathrm{DL}$ & $<\mathrm{DL}$ & $<\mathrm{DL}$ & $<\mathrm{DL}$ & $<\mathrm{DL}$ & $<\mathrm{DL}$ & 41 & 30 & 201 & 43 & 36 \\
\hline W1 & $<\mathrm{DL}$ & $<\mathrm{DL}$ & $<\mathrm{DL}$ & $<\mathrm{DL}$ & $<\mathrm{DL}$ & $<\mathrm{DL}$ & 38 & 18 & 424 & 37 & 90 \\
\hline W2 & $<\mathrm{DL}$ & $<\mathrm{DL}$ & $<\mathrm{DL}$ & $<\mathrm{DL}$ & $<\mathrm{DL}$ & $<\mathrm{DL}$ & 56 & 20 & 588 & 42 & 204 \\
\hline W3 & $<\mathrm{DL}$ & $<\mathrm{DL}$ & $<\mathrm{DL}$ & $<\mathrm{DL}$ & $<\mathrm{DL}$ & $<\mathrm{DL}$ & 54 & 11 & 779 & 44 & 354 \\
\hline W4 & $<\mathrm{DL}$ & $<\mathrm{DL}$ & $<\mathrm{DL}$ & $<\mathrm{DL}$ & $<\mathrm{DL}$ & $<\mathrm{DL}$ & 40 & 9 & 403 & 57 & 209 \\
\hline W5 & $<\mathrm{DL}$ & $<\mathrm{DL}$ & $<\mathrm{DL}$ & $<\mathrm{DL}$ & $<\mathrm{DL}$ & $<\mathrm{DL}$ & 36 & 12 & 441 & 54 & 115 \\
\hline W10 & $<\mathrm{DL}$ & $<\mathrm{DL}$ & $<\mathrm{DL}$ & $<\mathrm{DL}$ & $<\mathrm{DL}$ & $<\mathrm{DL}$ & 54 & 13 & 469 & 112 & 180 \\
\hline W5_w & $<\mathrm{DL}$ & $<\mathrm{DL}$ & $<\mathrm{DL}$ & $<\mathrm{DL}$ & $<\mathrm{DL}$ & $<\mathrm{DL}$ & 32 & 7 & 626 & 16 & 161 \\
\hline W10_w & $<\mathrm{DL}$ & $<\mathrm{DL}$ & $<\mathrm{DL}$ & $<\mathrm{DL}$ & $<\mathrm{DL}$ & $<\mathrm{DL}$ & 44 & 27 & 531 & 47 & 198 \\
\hline $\mathrm{DL}$ & 0.9 & 0.2 & 0.1 & 1.0 & 1.4 & 0.9 & - & - & - & - & - \\
\hline
\end{tabular}
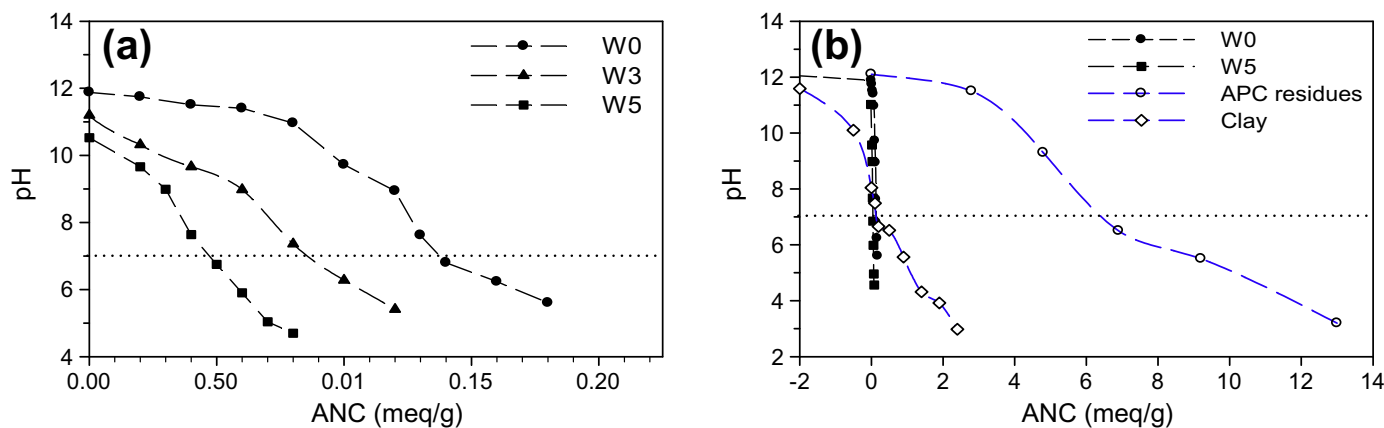

Fig. 8. Acid neutralization capacity of (a) LWA of type W0, W3 and W5 and (b) comparison with APC residues and clay.

or bases, and may reveal the sensitivity of a material itself to external influences and/or internal stresses (e.g. mineralization, organic matter degradation). Besides, the buffering capacity determines the evolution of the $\mathrm{pH}$ in the leachate over time. Fig. 8a depicts the ANC for formulations W0, W3 and W5 having as reference the $\mathrm{pH} 7$, and the most important conclusion is that even if the LWA were tested after milling, they exhibited a very low neutralization capacity (between 0.05 and $0.15 \mathrm{meq} / \mathrm{g}$ ). Indeed, Fig. 8b shows that ANC for LWA is significantly lower than the observed for the starting materials (clay and APC residues). This is a result of the sintering process, which provokes the degradation of calcite and the incorporation of Ca in the silicate matrix (van der Sloot et al., 2001). For this reason, it is very important to evaluate the sensitivity of LWA to external $\mathrm{pH}$, namely regarding the release
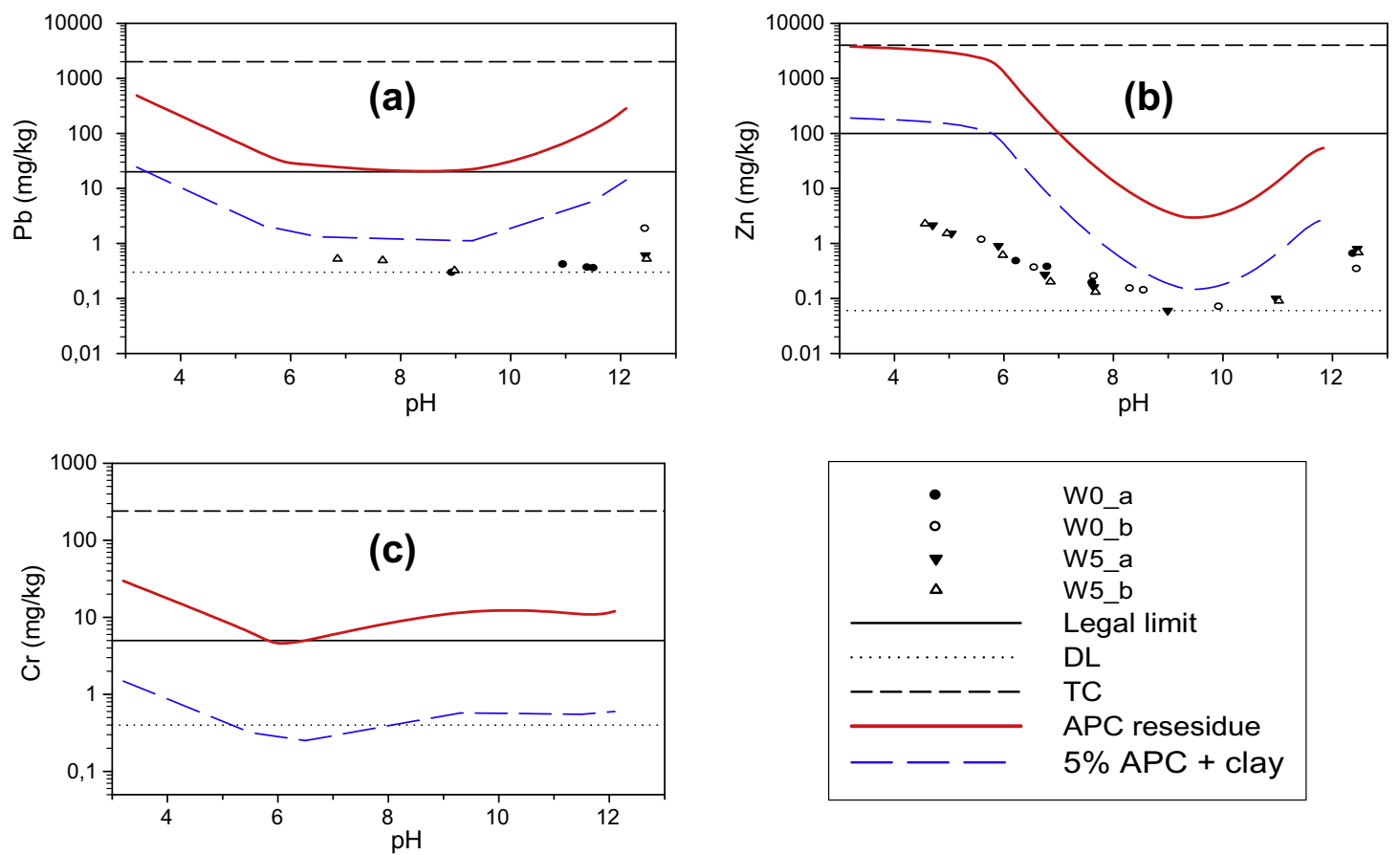

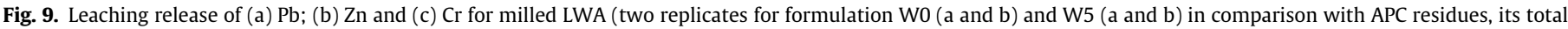
content (TC), the limit for deposition in hazardous landfill, and the detection limit (DL) of FAAS. 
of $\mathrm{Pb}, \mathrm{Zn}$ and $\mathrm{Cr}$, Fig. 9a-c. In each of these figures it was represented the leaching observed for two replicates of milled LWA with formulations W0 (without APC residues) and W5 (with 5\% of APC residues), the leaching observed for APC residues (Quina et al., 2009), the total content (TC), the limit for disposed of waste in hazardous landfill, and the detection limit of flame atomic absorption spectroscopy (FAAS). In the case of Pb, Fig. 9a, it was observed that the legal limit of $20 \mathrm{mg} / \mathrm{kg}$ is exceeded in the all range of $\mathrm{pH}$ for APC residues. However, after the incorporation of $5 \%$ of APC residues in LWA, the real leaching quantities are below the detection limit for all values of $\mathrm{pH}$. Even so, the curve referred as " $5 \%$ APC + clay" shows the situation that would be observed if immobilization did not occur. For the case of $\mathrm{Zn}$, Fig. 9b indicates that for $\mathrm{pH}$ lower than 7 the released quantities from LWA were above the detection limit, whilst far from the case referred to as " $5 \%$ APC + Clay", where it was assumed that immobilization did not occur. For the case of $\mathrm{Cr}$, Fig. 9c, all the released quantities were below the detection limit. Globally, these results show that if LWA were used in concrete for natural gravel replacement, where the predominant $\mathrm{pH}$ is above 12 , it is unlikely that leaching will have a significant environmental impact. In open storage, due to the low ANC, the leachate $\mathrm{pH}$ may decrease to below 7 , and a slightly higher undesired leaching might occur, but not exceeding environmental acceptable levels.

\section{Conclusions}

In this work, several formulations were tested in order to produce synthetic lightweight aggregates (LWA) in a laboratory oven, aiming at recycling air pollution control (APC) residues from MSW incineration. The morphology of the external glassy shell showed that more that $4 \%$ of APC residues as-received were very detrimental, leading to irregular external surfaces. However, for the case of a washing pre-treatment, the $5 \%$ of incorporation led to good results. In general, the bulk density and the compressive strength rose as APC residues amount increased, whereas the bloating index decreases. The water absorption capacity (WAC) increased as the amount of APC residues increase until 5\%, whereas when $10 \%$ of waste is used a reduction was measured. This parameter gives an indication about the open porosity, and thus depending on the application of the LWA, a high WAC may (or may not) be advantageous.

The leaching behavior was investigated using water and acidic solutions, and it was concluded that the environmental impact of heavy metals will not be significant. In spite of the low acid neutralization capacity of the LWA, their sensitivity to external $\mathrm{pH}$ variations was not relevant, since the pollutants were immobilized into the glassy ceramic matrix.

The main outcome of the work is that none beneficial effect was really identified by incorporating APC residues (with or without washing) into LWA. Accordingly, more research work is still required in order to divert this hazardous waste from landfills.

\section{References}

Castro, J., Keiser, L., Golias, M., Weiss, J., 2011. Absorption and desorption properties of fine lightweight aggregate for application to internally cured concrete mixtures. Cem. Conc. Compos. 33, 1001-1008.

Chandler, A.J., Eighmy, T.T., Hartlén, O., Kosson, D., Sawell, S.E., van der Sloot, H. Vehlow, J., IAWG-International Ash Working Group, 1997. Municipal Solid Waste Incinerator Residues, Studies in Environmental Science, vol. 67, Elsevier Science, Amsterdam.

Chandra, S., Berntsson, L., 2002. Lightweight Aggregate Concrete: Science Technology and Applications. William Andrew Publishing/Noyes Publications, New York.

Cheeseman, C.R., Makinde, A., Bethanis, S., 2005. Properties of lightweight aggregate produced by rapid sintering of incinerator bottom ash. Resour. Conserv. Recy. 43, 147-162.
Cheeseman, C.R., Virdi, G.S., 2005. Properties and microstructure of lightweight aggregate produced from sintered sewage sludge ash. Resour. Conserv. Recy. 45 $18-30$.

Chen, H.-J., Wang, S.-Y., Tang, C.-W., 2010. Reuse of incineration fly ashes and reaction ashes for manufacturing lightweight aggregate. Constr. Build. Mater. $24,46-55$.

Chiou, I.-J., Wang, K.-S., Chen, C.-H., Lin, Y.-T., 2006. Lightweight aggregate made from sewage sludge and incinerated ash. Waste Manage. 26, 1453-1461.

del Valle-Zermeño, R., Formosa, J., Chimenos, J.M., Martínez, M., Fernández, A.I., 2013. Aggregate material formulated with MSWI bottom ash and APC fly ash for use as secondary building material. Waste Manage. 33, 621-627.

Dimech, C., Cheeseman, C.R., Cook, S., Simon, J., Boccaccini, A.R., 2008. Production of sintered materials from air pollution control residues from waste incineration. J. Mater. Sci. 43, 4143-4151.

Ducman, V., Mladenovic, A., Suput, J.S., 2002. Lightweight aggregate based on waste glass and its alkalisilica reactivity. Cem. Conc. Res. 32, 223-226.

Ferreira, C., Ribeiro, A., Ottosen, L., 2003. Possible applications for municipal solid waste fly ash. J. Hazard. Mater. 96, 201-216.

Gennaro, R., Cappelletti, P., Cerri, G., Gennaro, M.,Dondi, M., Langella, A. 2004.Zeolitic tuffs as raw materials for lightweight aggregates. Appl. Clay Sci. 25, 71-81.

Gennaro, R., Cappelletti, P., Cerri, G., Gennaro, M., Dondi, M., Langella, A., 2005. Neapolitan Yellow Tuff as raw material for lightweight aggregates in lightweight structural concrete production. Appl. Clay Sci. 28, 309-319.

Gonzalez-Corrochano, B., Alonso-Azcarate, J., Rodas, M., 2009. Characterization of lightweight aggregates manufactured from washing aggregate sludge and fly ash. Resour. Conserv. Recy. 53, 571-581.

Gonzalez-Corrochano, B., Alonso-Azcarate, J., Rodas, M., 2012. Effect of thermal treatment on the retention of chemical elements in the structure of lightweight aggregates manufactured from contaminated mine soil and fly ash. Constr. Build. Mater. 35, 497-507.

Haiying, Z., Youcai, Z., Jingyu, Q., 2011. Utilization of municipal solid waste incineration (MSWI) fly ash in ceramic brick: product characterization and environmental toxicity. Waste Manage. 31, 331-341.

Huang, S.-C., Chang, F.-C., Lo, S.-L., Lee, M.-Y., Wang, C.-F., Lin, J.-D., 2007. Production of lightweight aggregates from mining residues, heavy metal sludge, and incinerator fly ash. J. Hazard. Mater. 144, 52-58.

Hwang, C.-L., Bui, L.A., Lin, K.-L., Lo, C.-T., 2012. Manufacture and performance of lightweight aggregate from municipal solid waste incinerator fly ash and reservoir sediment for self-consolidating lightweight concrete. Cem. Concr. Compos. 34, 1159-1166.

Kourti, I., Cheeseman, C.R., 2010. Properties and microstructure of lightweight aggregate produced from lignite coal fly ash and recycled glass. Resour. Conserv. Recy. 54, 769-775.

Latosinska, J., Zygadlo, M., 2011. The application of sewage sludge as an expanding agent in the production of lightweight expanded clay aggregate mass. Environ. Technol. 32, 1471-1478.

Mangialardi, T., 2001. Sintering of MSW fly ash for reuse as a concrete aggregate. J. Hazard. Mater. 87, 225-239.

Qiao, X.C., Ng, B.R., Tyrer, M., Poon, C.S., Cheeseman, C.R., 2008. Production of lightweight concrete using incinerator bottom ash. Constr. Build. Mater. 22, 473-480.

Quina, M.J., Quinta-Ferreira, R.M., 2002. Properties of a recent hazardous waste in Portugal. Adv. Mater Forum I - Key Eng. Mater. 230-232, 400-403.

Quina, M.J., Almeida, M.A., Santos, R., Bordado, J.C., Quinta-Ferreira, R.M., 2006. Prediction of solid waste incineration residues quantity for valorization in lightweight aggregates. Adv. Mater. Forum III - Part 2 - Mater. Sci. Forum, $1731-1735$.

Quina, M.J., Bordado, J.C., Quinta-Ferreira, R.M., 2008a. Treatment and use of air pollution control residues from MSW incineration: an overview. Waste Manage. 28, 2097-2121.

Quina, M.J., Santos, R.C., Bordado, J.C., Quinta-Ferreira, R.M., 2008b. Characterization of air pollution control residues produced in a municipal solid waste incinerator in Portugal. J. Hazard. Mater. 152, 853-869.

Quina, M.J., Bordado, J.C., Quinta-Ferreira, R.M., 2009. The influence of pH on the leaching behaviour of inorganic components from municipal solid waste incineration APC residues. Waste Manage. 29, 2483-2493.

Quina, M.J., Bordado, J.C., Quinta-Ferreira, R.M., 2010. Chemical stabilisation of air pollution control residues from municipal solid waste incineration. J. Hazard. Mater. 179, 382-392.

Quina, M.J., Bordado, J.C., Quinta-Ferreira, R.M., 2011a. Percolation and batch leaching tests to assess release of inorganic pollutants from municipal solid waste incinerator residues. Waste Manage. 31, 236-245.

Quina, M.J., Bordado, J.C., Quinta-Ferreira, R.M., 2011b. Environmental impact of APC residues from municipal solid waste incineration: reuse assessment based on soil and surface water protection criteria. Waste Manage. 31, 1984-1991.

Sabbas, T., Polettini, A., Pomi, R., Astrup, T., Hjelmar, O., Mostbauer, P., Cappai, G., Magel, G., Salhofer, S., Speiser, C., Heuss-Assbichler, S., Klein, R., Lechber, P., 2003. Management of municipal solid waste incineration residues. Waste Manage. 23, 61-88.

Sakai, S., Hiraoka, M., 2000. Municipal solid waste incinerator residue recycling by thermal processes. Waste Manage. 20, 249-258.

Tan, W.-F., Wang, L., Huang, C., Liu, Y.Y., Green, J.E., Newport, D., Green, T., 2012. Utilization of municipal solid waste incineration fly ash in lightweight aggregates. J. Central South Univ. Technol. 19, 835-841.

van der Sloot, H.A., Hoede, D., Cresswell, D.J.F., Barton, J.R., 2001. Leaching behaviour of synthetic aggregates. Waste Manage. 21, 221-228. 
Wainwright, P.J., Cresswell, D.J.F., 2001. Synthetic aggregates from combustion ashes using an innovative rotary kiln. Waste Manage. 21, 241-246.

Wang, K.-S., Chiang, K.-Y., Perng, J.-K., Sun, C.-J., 1998. The characteristics study on sintering of municipal solid waste incinerator ashes. J. Hazard. Mater. 59, 201-219.
Wang, K.-S., Sun, C.-J., Yeh, C.C., 2002. The thermotreatment of MSW incinerator fly ash for use as an aggregate: a study of the characteristics of size-fractioning. Resour. Conserv. Recy. 35, 177-190. 